\title{
Effects of orthodontic forces on pulp tissue
}

\author{
Pinandi Sri Pudyani \\ Department of Orthodontic \\ Faculty of Dentistry Gadjah Mada University \\ Yogyakarta - Indonesia
}

\begin{abstract}
Numerous researches on pulp tissue changes caused by orthodontic forces have been performed, among others are: pulp angiogenesis, pulp tissue respiration rate, alkaline phosphatase and aspartate aminotransferase enzyme activities; micro vascular response inside the pulp and the effect of dental movement i.e. extrusion, intrusion, and torque. The result is still controversial, as some researchers claim that orthodontic force has a negative effect, others deny by saying there is no such effect on pulp tissue.
\end{abstract}

Key words: pulp tissue, orthodontic force

Correspondence: Pinandi Sri Pudyani, c/o: Bagian Ortodonsia, Fakultas Kedokteran Gigi Universitas Gadjah Mada. Jln. Denta No. II Sekip Utara Yogyakarta 55281, Indonesia.

\section{INTRODUCTION}

For years, pulp tissue response to orthodontic forces has been studied by researchers, so far, the results are controversial. ${ }^{1-3}$ Histological test on previous studies show severe pulp degeneration in every observed case. It is said that the orthodontic forces has blocked collateral circulation, while pulp is the most sensitive tissue in human body. It is concluded that pulp tissue damage can not be avoided during orthodontic treatment. ${ }^{1}$

Previous researchers stated that orthodontic forces had a negative effect on pulp tissue. The research result through a histological test, showed that dental pulp was influenced by orthodontic dental movement, it was proven by pulp reaction i.e. disrupted blood circulation, and necrosis. ${ }^{4}$ On the contrary, other researchers testified that orthodontic forces had no prolonged significant negative effect on pulp. ${ }^{3}$

Numerous researches on pulp tissue changes caused by orthodontic forces have been performed, among others are: pulp tissue respiration rate, ${ }^{1}$ pulp angiogenesis, ${ }^{2}$ pulp tissue response due to dental extrusion, ${ }^{4}$ aspartate aminotransferase ${ }^{3,5}$ and alkaline phosphatase ${ }^{6,7}$ enzyme activities and pulp micro vascular response. ${ }^{8}$

The writing aims at studying the effects of dental pulp tissue after subjected to various orthodontic forces.

\section{Pulp tissue response caused by dental extrusive force}

To learn the pulp tissue response after dental extrusion, the study was conducted on 2 research groups i.e. dental extrusion group with sectional system of $75 \mathrm{~g}$ force, and dental extrusion group with $1 / 4$ inch elastic $-4.5 \mathrm{oz}$. force. After 10 days extrusion observation, both groups showed no inflammation response either in the pulp or in the hard tissue, but there was a pulp stone forming on several cases of both groups. After 40 days dental extrusion, the first group showed two cases of light pulp inflammation reaction and big pulp stone forming; while in the second group there was no inflammation cell infiltration, no soft tissue changes and no deposition of reparative dentin on all cases. ${ }^{5}$

\section{Pulp tissue response caused by dental intrusive force}

Several researchers believed that intrusive orthodontic force can harm microcirculation of the pulp. ${ }^{2,8,9}$ Intrusion or other dental movement can obstruct pulp inside circulation causing pulp damage. One of the researchers said that the use of light force interrupted by several breaks will definitely decrease pulpal iatrogenic process, therefore, it was advisable to give an orthodontic force not more than a capillary pressure of $20 \mathrm{~mm} / \mathrm{Hg}$, because blood constriction can be followed by necrosis. Excessive intrusion and extrusion will lead to necrotic pulp tissue without any odontoblast layer regeneration. It was noticed that teeth with open apical foramen was prone to receive the impact of dental intrusion. ${ }^{8}$

Statement in pertaining to the effect of apical foramen was still controversial, some researchers considered that the impact of intrusion depended on root forming stage. Teeth with opened apex had better prognosis. The majority of researchers stated that orthodontic force will cause hyperemi, diapedesis, white blood cell marginalization, and vacuoles forming on odontoblast layer. ${ }^{8}$ Although the intrusive pressure was light, it can cause hyperemic pulp and decreased blood circulation into the pulp. ${ }^{8,10}$ Excessive force will end in an irreversible pulp damage. ${ }^{11,12,13}$

The decreases in pulpal blood flow was of brief duration (averaging approximately 32 minutes) and was followed by a prolonged period (48 hours). Of the possible force vectors that can be applied to teeth during orthodontic 
treatment, intrusion is thought to have the greatest impact on the apical region, it can continue to constrict the pulp, inhibiting pulpal blood supply. Intrusive forces might move the apex of the tooth into close proximity with the base of the bony socket and thus compress the periapical blood vessels. ${ }^{10,13}$ A light intrusive force of 50 gm in 60 days on premolars caused a compression on monkey's periodontal ligament. ${ }^{14}$ Light force of 5-25 gm per maxillary incisor was recommended for clinical intrusion, although higher force can be utilized with anterior high pull head gear. ${ }^{15,16}$

Short duration dental intrusion impact on pulpal blood circulation had been analyzed using a laser Doppler flowmetry probe. The results were: no changes of blood circulation in the pulp after a brief intrusive orthodontic force and there was only $19 \%$ blood circulation decrease compared to control group, meaning a non-significant difference. ${ }^{10}$ The orthodontic force had an impact on pulp tissue by decreasing $27 \%$ of pulp tissue respiration rate. There was a positive correlation between age and the pulpal tissue respiration decrease. It was concluded that a short duration orthodontic force can produce biochemical and biologic changes on pulp tissue, and there was a bigger risk for older orthodontic patients. ${ }^{1}$

\section{Pulp angiogenesis during orthodontic dental movement}

Angiogenic changes in pulp tissue during orthodontic teeth movements remain unknown. Angiogenesis is the growth of new capillary structures before the organization into larger structures through the neovascularization process. Angiogenesis may be found in embryo formation, tissue growth, healing of wounds, in an inflammation process and pathology related to growth of blood vessels. ${ }^{2}$

The research was done on 30 premolars which were extracted due to orthodontic treatment and contra-lateral teeth were used as control. The instrument used was a straight wire system on $0.5-1 \mathrm{~N}$ power for 2 weeks. Brackets were placed from the second right to the second left premolars except on the teeth being used as control. The technique utilized was a 3-dimensional proliferative assay based on a previous research. Observation of tissue culture was done on the $5^{\text {th }}$ and $10^{\text {th }}$ day. It was reported that micro-blood vessels were discovered on the $5^{\text {th }}$ day and their growth was to reach its apex on the $8^{\text {th }}$ day to the $10^{\text {th }}$. The amount of micro-blood vessels was more easily found significantly on pulp tissue that was moved than the control group on the $5^{\text {th }}$ and $10^{\text {th }}$ day. ${ }^{2}$

\footnotetext{
Alkaline phosphatase activity on pulp tissue after subjected to orthodontic force

Alkaline phosphatase (ALP) is an enzyme which is related to mineralization of tissue $\mathrm{e}^{6,7}$ and found on the matrix vesicle of mineralized tissue. Alkaline phosphatase plays a role in the early process of mineral deposition and calcification; and matrix vesicle plays an important role in the growth of extra-cellular matrix and tissue
}

mineralization. A high ALP activity can be seen on the pulp and can be detected in cells under the odontoblast cellular layer. ${ }^{6}$

Several cells in the dental pulp such as fibroblast and odontoblast can synthesize ALP. Alkaline phospatase activity in human pulp is 8 times higher in reversible pulp inflammations and in irreversible inflammations is almost equal to normal pulp. ${ }^{6}$ This shows how ALP plays a role in the metabolic shift of dental pulp and other organs. Perinetti et al. ${ }^{7}$ conducted a research on ALP activity in the pulp during orthodontic treatment on 16 patients. The measurement of ALP activity was done on premolars which were extracted due to orthodontic treatment. Dental extraction was done after 7 days of treatment. Measurement of ALP activity was done using visible UV spectrophotometer on $405 \mathrm{~mm}$ for 4 minutes. There was a significant decrease in ALP activity on orthodontic patients.

\section{Aspartate aminotransferase (AST) activity}

Aspartate aminotransferase is an intra-cellular cytoplasmic enzyme and released to the extra-cellular in dead cells, and its activity in the extra-cellular environment can be considered as a sign of necrosis. ${ }^{3,5}$ Even so the base AST level in the extra-cellular environment can also be detected as a turnover of the physiological tissue which results in the possibility of detecting AST in healthy and inflammed pulp tissue. ${ }^{3}$ The results showed an increase of AST in reversible pulp inflammations $(7.98 \pm 2,1 \mathrm{unit} / \mathrm{mg}$ of pulp tissue), a decrease in irreversible inflammations $(2.28 \pm 1,7 \mathrm{unit} / \mathrm{mg})$ while in normal pulp tissue is $4.8 \pm 0,7 \mathrm{unit} / \mathrm{mg}$.

Perinetti et al. ${ }^{3}$ conducted a research on 17 patients where the first premolar tooth was extracted due to treatment with the straight wire system. The force used was 30-90 g. Measurement was done after 7 days of treatment using visible UV spectrophotometer. The results showed a significant increase of AST activity in dental pulp being subjected to orthodontic force $(6.7 \pm 1.9$ unit $/ \mathrm{mg}$ of pulp tissue) and in the control group the result was $3.6 \pm 1.4 \mathrm{unit} / \mathrm{mg}$. The increase of AST activity was also found in the gingival crevicular liquid due to inflammation process $^{17}$ and orthodontic force on teeth. ${ }^{18}$

\section{Changes in dental pulp tissue histology due to orthodontic force}

The research was conducted by applying torque movements on mandible incisors and bodily movements on mandible incisors in another group. Treatment used the Edgewise system by placing bands on the teeth and the size of the bracket slots were 0.18 inches with anchors on the canines. Length of treatment was 21 days. The results of the treated group were as follows: teeth which were moved bodily showed an increase in the quantity of collagen fibers in the whole pulp and a decrease in cellular concentration. A decrease in fibroblast cells and 
an increase in inflammed cells especially in the pulp crown area were also happened. Blood flow was disrupted, number of blood vessels went down and were narrower compared to the control group. There was a extravasation of red blood cells and odontoblast damage which was varied according to the force applied to teeth. On torque movement to the lingual, there was odontoblast damage on the middle third of the root, and cellular damage on the labial and lingual side of apical section of dental pulp. ${ }^{9}$

\section{DISCUSSION}

The effect of orthodontic force on varied dental orthodontic movements on pulp tissue so far is a controversial problem faced by researchers. Most of researchers $1,3,7,9$ stated that orthodontic force presents a negative impact on pulp tissue, whereas other researchers said that orthodontic force creates no specific impact on pulp tissue. ${ }^{4,10,19}$

The result research on pulp tissue reaction towards orthodontic force, found histological tissue changes on almost all observed cases. The most frequent changes discovered were damages on odontoblast layer. The damage level depended upon the given force. On torque movements, the damage was in the middle third of the root, which was in accordance with the fulcrum of the teeth. On bodily movements, odontoblast damage was found on the pressured- as well as on the stretched-areas. The time-span of cellular damage fitted to the length of cellular activity on alveolar bone next to the bodily-moved tooth. Odontoblast damage on bodily movements spread out to the dental root. This histological change was due to dental internal structure which was unable to stand an orthodontic force causing an impact on dental internal histomorphology, ${ }^{9}$ but further studies on pulp tissue after subjected to orthodontic force, found no significant difference. Pulp hyperemi occurred only after the activation. It was concluded that orthodontic force yielded no significant difference on pulp vascular system. ${ }^{19}$

In relation to the rate of pulp tissue respiration caused by orthodontic force, it was reported that 72 hours of orthodontic force can decrease $27 \%$ of the respiration rate of human premolars. It was assumed that the decrease of tissue respiration will give a negative impact to cellular activities, particularly to the intracellular metabolism (in a biochemical manner). The decrease of pulp tissue respiration was not caused by cellular changes alone, but also by the changes of pulp tissue stroma around dental supporting tissues. The influencing factors to the changes were blood constriction and halted blood flow to the pulp., ${ }^{1,9}$

Orthodontic force caused lots of micro-blood vessels forming found on the $5^{\text {th }}$ day observation, and the peak forming was on the $10^{\text {th }}$ day. This phenomenon was believed as a response of an increased angiogenic development factor in pertaining to orthodontic force. ${ }^{2}$
Orthodontic force generated changes alkaline phosphatase (ALP) ${ }^{7}$ and aspartate aminotransferase (AST) activities. ${ }^{3}$ Alkaline phosphatase played an important role in the physiologic and pathologic pulp tissue mineralization. Studies of ALP activity on pulp tissue after subjected to orthodontic force, showed a decrease. It was concluded that orthodontic force did not broaden the predentin layer and did not form pulp stone either. The decrease of ALP activity -as a consequence of the presence of orthodontic strength- was probably caused by damaged cells inside the pulp which were responsive to ALP enzyme. Due to the fact that pulp cells i.e. fibroblast and odontoblast also synthesized ALP, the decrease of ALP could also be caused by disturbances of the cells. ${ }^{7}$

Studies on orthodontic impact towards pulp tissue were also conducted on aspartate aminotransferase (AST) activity. The AST activity was used to predict pulp necrosis. 3,9 A necrotic process was related to blood constriction and the halted pulp blood flow after the teeth were subjected to orthodontic force, causing the decrease of pulp oxygen. ${ }^{1,20}$ Upon receiving a 30-90 g orthodontic force for 7 days, the teeth showed a significant increase of AST activity in dental pulp, and it assumed to be the initiation of an inflammation process. The decrease of tissue respiration rate and the increase of pulp tissue apoptosis were factors to influence AST increased activity. ${ }^{8,21}$ These changes had constricted and stopped pulp blood flow. The decrease of blood flow to the pulp caused the decrease of oxygen content and alkalinity of pulp tissue.3,19,21

Orthodontic force impact on apoptosis i.e. cell death program was already examined.22 Measurement was done by TUNEL (Terminal deoxynucleotidyl by transferasemediated dUTP nick and labeling) reaction, by counting the TUNEL-positive cells. The study showed that maximal apoptosis occurred 3 days after application of the appliance. Most TUNEL-positive cells were found in the periapical area and inside the pulp tissue of the first and second molars. Possibly, it was caused by high proliverative activity and cell turnover in the pulp cavity. TUNEL-positive cells might be osteocytes, osteoblast and macrophages. Generally the apoptotic body will be deleted by macrophages and there was no inflammation reaction during apoptosis process.

Various orthodontic force to move teeth will produce pulp tissue changes, among other is a dental extrusion movement. ${ }^{4}$ Many studies show no inflammation reaction on treated teeth, but it shows an odontoblast aspiration into dental tubules $(22.5 \%)$ on several teeth. Histological data shows that there is no pathological changes on pulp tissue on 10-40 days dental extrusion with $75 \mathrm{~g}$ initial force. The same thing happens to $10-40$ days dental intrusion with $4.5 \mathrm{oz}$ elastic. It is said that $25-30 \mathrm{~g}$ dental extrusion force on adults can prevent the damage of pulp tissue. It is concluded that the extrusive force used in this research, has not caused significant degenerated odontoblast. ${ }^{4}$

Intrusive force must be carefully counted so that no impending damage occur to pulp or to dental supporting- 
tissues as well. ${ }^{10,23}$ A $4500 \mathrm{gm}$ intrusive force is the force to be used to incisor teeth. ${ }^{10}$ The force utilization is based on an estimation that a tooth will move $0.028 \mathrm{~mm}$ as a response to $1000 \mathrm{gm}$ force in 15 seconds. This is the force commonly used in orthodontic clinics, where no disturbances of pulpal blood flow take place, as a result of the incapability of the intrusive force to move the apical part.

Short duration force is presumably not strong enough to press periodontal ligament. Dental movement of 0.028 $\mathrm{mm}$, the average of periodontal ligament width at the apex is between $0.18-0.21 \mathrm{~mm}$, then the resulting reduction of less than $17 \%$ periodontal space may be insufficient to compress the apical vasculature. It is assumed that compression of the periodontal ligament of one third or less will not alter its blood circulation. Moreover, even quite heavy force may not easily cause excessive apical tooth movement because of the mechanical properties of the periodontal ligament that resist displacement. Collagen fibers inside the periodontal ligament are oriented to resist intrusive forces and remain rigid when force application is brief. 10

The conclusion reveals that it is compulsory to measure thoroughly the force to move teeth in orthodontic manner. Several factors to be taken into account are: movement type, the size of given force, and patient's age in relation to dental periapical condition. This consideration is based on studies which stated the negative impact of orthodontic force on pulp tissue. It is advisable to give force not more than a capillary pressure of $20 \mathrm{~mm} / \mathrm{Hg}$ in order to prevent the disruption of blood circulation into the pulp which can be followed by a pulp tissue necrosis.

\section{REFERENCES}

1. Hamersky PA, Weimer AD, Taintor JF. The effect of orthodontic force application on the pulpal tissue respiration rate in the human premolar. Am J Orthod 1980; 77(4):368-78.

2. Derringer KA, Jaggers DC, Linden RWA. Angiogenesis in human dental pulp following orthodontic tooth movement. J Dent Res 1996; 75(10):1761-66.

3. Perinetti G, Varvara G, Festa F, Esposito P. Aspartate aminotransferase activity in pulp of orthodontically treated teeth. Am J Orthod Dentofac Orthop 2004; 125(1):88-92.

4. Subay RK, Kaya H, Tarim B, Subay A, Cox CF. Response of human pulpal tissue to orthodontic extrusive applications. J Endod 2001; 27(8):508-11.
5. Spoto GS, Fioroni M, Rubini C, Tripodi D, Perinetti G, Piatelli A. Aspartate aminotransferase activity in human healthy and inflammed dental pulps. J Endod 2001; 27(6):394-95.

6. Spoto G, Fioroni M, Rubini C, Tripodi D, Stilio MD, Piattelli A. Alkaline phosphatase activity in normal and inflammed dental pulps. J Endod 2001; 27(3):180-2.

7. Perinetti G, Varvare G, Salini L, Tete S. Alkaline phosphatase activity in dental pulp of orthodontically treated teeth. Am J Orthod Dentofac Orthop 2005; 128(4):492-6.

8. Guevara M, McClugage SG. Effects of intrusive forces upon the microvasculature of the dental pulp. Angle Orthod 1980; 50(2):129-34.

9. Anstendig HS, Kronman JH. A histologic study of pulpal reaction to orthodontic tooth movement in dogs. Am J Orthod 1972; 42(1):50-5.

10. Barwick PJ, Ramsay DS. Effect of brief intrusive force on human pulpal blood flow. Am J Orthod Dentofac Orthop 1996; 110(3):273-9.

11. Graber TM. Orthodontic principles and practice. $3^{\text {rd }}$ ed. Philadelphia, Pennsylvania: WB Saunders; 1972.

12. Graber TM, Swain BF. Current orthodontics concepts and techniques. $2^{\text {nd }}$ ed. Philadelphia, Pennsylvania: WB Saunders; 1975.

13. Dermaut LR, De Munk A. Apical root resorption of upper incisors caused by intrusive tooth movement: a radiographic study. Am J Orthod 1986; 90(4):321-6.

14. Dellinger EL. A histologic and cephalometric investigation of premolar intrusion in the Macaca speciosa monkey. Am J Orthod 1969; 53(3):325-55.

15. Burstone CR. Deep over bite correction by intrusion. Am J Orthod 1977; 72(1):1-22.

16. Melsen B, Agerbaek N, Markenstam G. Intrusion of incisors in adult patients with marginal bone loss. Am J Orhod Dentofac Orthop 1989; 96(3):232-41.

17. Chambers DA, Crawford JM, Mukerjee S, Cohen RL. Aspartate aminotransferase in crevicular fluid during experimental gingiva in beagle dogs. J Periodontol 1984; 55(4):525-30.

18. Perinetti G, Paolantonio M, D Attilio M, D Archivio D, Dolci M, Femminella B. et al. Aspartate aminotransferase activity in gingival crevicular fluid during human orthodontic treatment. A controlled shrt-term longitudinal study. J periodontol 2003; (1):145-52.

19. Nixon CE, Saviano JA, King GJ, Keeling SD. Histomorphometric study of dental pulp during orthodontic tooth movement. J Endod 1993; 19(1):13-6.

20. Unterscher RE, Nieberg LG, Weimer AD, Dyer JK. The response of human pulpal tissue after orthodontic force application. Am J Orthod Dentofac Orthop 1987; 92(3):220-4.

21. Stenvik A, Mjor IA. Pulp and dentine reactions to experimental tooth intrusion: a histologic study of the initial changes. Am J Orthod 1970; 57(3):370-85.

22. Rana MW, Pothisiri V, Killiany DM, Xu XM. Detection of apoptosis during orthodontic tooth movement in rats. Am J Orthod Dentofac Orthop 2001; 119(5):516-21.

23. Mc Fadden WM, Engstrom C, Engstrom H, Anhoim JM. A study of the relationship between incisor intrusion and root shortening. Am J Orthod Dentofac Orthop 1989; 96(5):390-6. 